\title{
Implementation of Bidirectional LLC Resonant Converter for RES with Automatic Transition
}

\author{
Ajith Kumar $\mathbf{N}^{1}$, Dhanalakshmi $\mathbf{R}^{\mathbf{2}}$ \\ PG Student, Department of Electrical and Electronics Engg, DSCE, Bangalore, India ${ }^{1}$ \\ Professor, Department of Electrical and Electronics Engg, DSCE, Bangalore, India ${ }^{2}$
}

\begin{abstract}
This paper presents the hardware implementation of the bidirectional LLC resonant converter used for renewable energy sources and energy storage systems with automatic mode transition. Out of the various bi-directional DC-DC converters, LLC resonant converters have gained an immense interest due its simple structure, buck/boost operation capability and narrow switching frequency variation range and higher efficiency than other converters. With this proposed new bi-directional LLC resonant dc-dc converter, the power flow direction and output power of the proposed converter can be changed automatically and continuously, which is attractive for energy storage systems to keep the dc-bus voltage constant and to keep the balance of energy. The desired characteristics of the proposed topology will obtained and analyzed. The analysis of the proposed Power flow converters for Distributed Generation with automatic bidirectional Transition will be carried out using MATLAB simulation package and the results will be verified by the construction of prototype model.
\end{abstract}

Keywords: Distributed Generation (DG), Renewable energy sources (RES), Energy storage systems, LLC resonant converter \&automatic transition.

\section{INTRODUCTION}

Electrical energy constitutes for one-third of the energy used in the world due to its cleaner form, efficient usage and other advantages. The energy saving and environmental protection gains immense interest in recent research activities. Usage of renewable energy resources to generate electricity often leads to many challenges which are out of human control. This makes way to employ energy storage systems along with renewable energy sources for the desired operations. The combination of ESS and RES should have the property of bidirectional power flow to ensure quality and reliable power at user end. Thus we need efficient and reliable bidirectional converters.

In general, bidirectional dc-dc converters for ESSs should have attractive characteristics in power density, efficiency, and reliability. Millions of bidirectional dc-dc topologies have been proposed and evaluated in recent years. The dual active bridge (DAB) converter has found immense research interests.

This converter has two bridge type converters in each side of the power transformer, and the phase shift angle between the primary side converter and the secondary side converter determines the power flow direction and its output power. But the reverse energy and turn-off power loss is higher in this converter which reduces the overall efficiency and hence the performance. An improved DAB topology with reduced reverse energy and simple control scheme was proposed but the topology lost the bidirectional power flow capability. Several control methods with two or more phase shift angles as control variables were proposed to minimize the reverse energy but the control methods were a little bit complex and the turn-off loss was still high.

\section{LITERATURE SURVEY}

Paper [1] proposes a new soft-switching bidirectional DCDC converter. The proposed converter achieves ZVS for the entire main switches and ZCS for the rectifier diodes in the large load range. These features reduce the switching losses, voltage and current stresses and diode reverse recovery effect.

Whereas the paper [2] has reviewed a non-isolated bidirectional dc-dc converters which finds application in plug-in hybrid electric vehicles with charging facilities with optimized operation of the converter by employing soft switching technique. Three DC/DC converter topologies suitable for high power density applications are presented in the paper [3]. All three topologies are operated in soft switching manner, making possible a reduction in switching losses and an increase in switching frequency. The three phase dual-bridge converter proposed is shown to have the most favourable characteristics.

In paper [4] first describes the need of a bi-directional DC to DC converter for a fuel cell system. Various combinations of current-fed and voltage-fed converters are explored for the application of different voltage levels. With a preliminary study, putting current-fed on low- 


\section{IJIREEICE \\ International Journal of Innovative Research in Electrical, Electronics, Instrumentation and Control Engineering ISO 3297:2007 Certified \\ Vol. 5, Issue 1, January 2017}

voltage side and voltage fed on high voltage side indicated higher efficiency than the other way around. Two low-side circuit topologies were then selected for hardware implementation. One is the L-type half-bridge current-fed converter, and the other is full-bridge current-fed converter.The main aim in the paper [5] is to improve the performance of high current dual active bridge converters when operated over a wide voltage range. A typical application is for fuel cell vehicles where a bi-directional interface between a $12 \mathrm{~V}$ battery and a high voltage DC bus is required.Careful analysis shows that the high currents on the battery side cause significant design issues in order to obtain a high efficiency. The standard phase shift modulation method can result in high conduction and switching losses. This paper proposes a combined triangular and trapezoidal modulation method to reduce losses over the wide operating range.

A soft-commutating method and control scheme for an isolated boost full bridge converter is proposed in this paper [6] to implement dual operation of the well-known soft-switching full bridge $\mathrm{dc} / \mathrm{dc}$ buck converter for bidirectional high power applications. It provides unique commutation logic to minimize a mismatch between current in the current-fed inductor and current in the leakage inductance of the transformer when commutation takes place, significantly reducing the power rating for a voltage clamping snubber and enabling use of a simple passive clamped snubber. To minimize the mismatch, the method and control scheme utilizes the resonant tank and freewheeling path in the existing full bridge inverter at the voltage-fed side to preset the current in the leakage inductance of the transformer in a resonant manner.

Paper [7], [8] \& [9] addresses a bidirectional dc-dc converter suitable for an energy storage system with an additional function of galvanic isolation, usage of transformer and automotive applications. An energy storage device such as an electric double layer capacitor is directly connected to a dc side of the dc-dc converter without any chopper circuit.Paper [10] proposes a bidirectional converter for higher power applications with better performance. Paper [11] proposes a new bidirectional LLC resonant converter which can be adopted for high power applications. This LLC resonant converter helps to achieve soft switching and hence the overall efficiency of the converter will be higher than rest of the converters.

In this paper we proposed a topology where a new control scheme is established where all the switches can achieve soft switching and the reverse energy flow is reduced dramatically. The power flow direction as well the output power can be controlled continuously. This attractive feature gains much interest in energy storage applications to maintain the constant voltage at bus in order to keep the energy at balance. To make both the forward mode and the backward mode operation symmetric an auxiliary inductor is introduced into the circuit. All the switches in both the sides of the transformers are turn ON and OFF with the same switching frequency whereas the pulse width is not same. The voltage gain decides the pulse width.

\section{III.SYSTEM DESCRIPTION}

Distributed generation (DG) system plays an important role in utilizing the cleaner energy sources and also in providing the quality power to the end users. Renewable energy sources may provide the eco-friendly electricity but their intermittent nature leads to the power quality issues as well failure in meeting the load demand. Hence for the continuous supply to the end users along with the cleaner energy sources usage of conventional energy sources such as diesel generators etc. can supply the power continuously. Thus the DG systems are necessary in the modern days to meet the load in an optimised usage of renewable and cleaner energy sources to maintain the continuous supply to customers. A typical DG system is as shown in figure 1 .

Energy storage systems (ESSs) are necessary to deal with such issues so that the quality of the power can be enhanced for grid-tied and off grid applications with reliability. Batteries and super capacitors are the most popular energy storage components considering the price and performance. The ESSs should have bidirectional power flow capability to store the excess energy generated by renewable resources, and release it when the renewable energy is not sufficient or during peak times of energy consumption. So, the bidirectional dc-dc converter is a key component in ESSs to enable the bidirectional power flow.

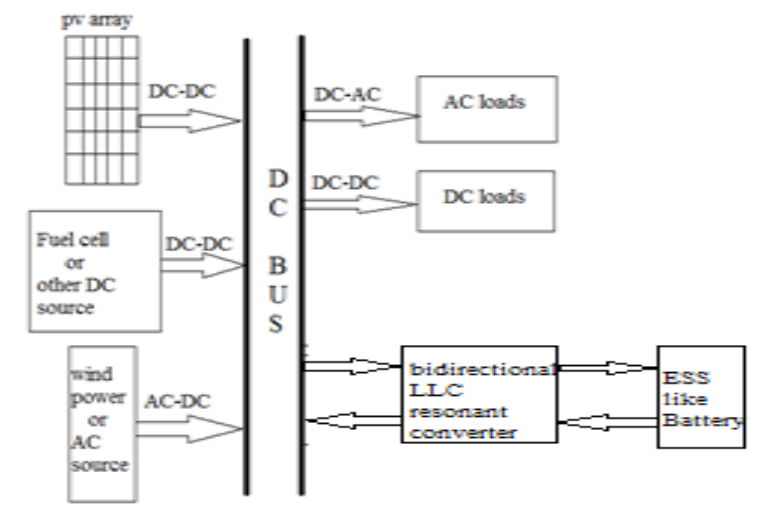

Fig1. Typical DG system

In general, bidirectional dc-dc converters for ESSs should have attractive characteristics in power density, efficiency, and reliability. Millions of bidirectional dc-dc topologies have been proposed and evaluated in recent years. The dual active bridge (DAB) converter has found immense research interests. This converter has two bridge type converters in each side of the power transformer, and the phase shift angle between the primary side converter and 


\section{IJIREEICE \\ International Journal of Innovative Research in Electrical, Electronics, Instrumentation and Control Engineering ISO 3297:2007 Certified \\ Vol. 5, Issue 1, January 2017}

the secondary side converter determines the power flow direction and its output power. But the reverse energy and turn-off power loss is higher in this converter which reduces the overall efficiency and hence the performance. An improved DAB topology with reduced reverse energy and simple control scheme was proposed but the topology lost the bidirectional power flow capability. Several control methods with two or more phase shift angles as control variables were proposed to minimize the reverse energy but the control methods were a little bit complex and the turn-off loss was still high.

\section{CONVENTIONAL LLC RESONANT CONVERTER}

Among the various kinds of resonant converters, the LLC resonant converter has superior performance compared to the other resonance configurations; it has capability of buck/boost operation and variation in narrow switching frequency. This LLC resonant converter has improved efficiency $(93 \%-96 \%)$. The LLC resonant converter is a single compact device used to achieve soft switching in the bidirectional converters. The main goal of this conventional LLC resonant converter is to achieve bidirectional power flow and also to gain the capability to maintain buck/boost operation in any operational mode. An extra inductor called as auxiliary inductor is introduced in the circuit configuration in the primary side of the transformer to achieve the soft switching of the converter. The output is regulated by the switching frequency modulation and the switches are controlled with $50 \%$ duty cycle as traditional LLC resonant converter. In this LLC resonant converter, all the switches in input side can achieve zero voltage switching and switches in output side can achieve zero current switching. All the switches in both the sides of the transformer are operated at same switching frequency in order to prevent flow of current in the body diodes of MOSFETS.

The auxiliary inductor doesn't affect the operating principle in forward mode but it helps in achieving the soft switching of the switches in the primary side. Soft current commutation between the switches in the secondary side can be achieved as like in the conventional LLC resonant converter when the operating switching frequency is equal or above the resonant frequency. Where as in the case when operating switching frequency is lower than the resonant frequency, soft commutation of current in the secondary side cannot be achieved. As a result of which there exists a small circulating energy. Even though the turn off current of the secondary side switches is very small, it affects the performance of the DAB converter.

\section{OPERATING PRINCIPLE OF THE PROPOSED LLC RESONANT CONVERTER}

Fig.2 shows the circuit arrangement of the proposed LLC resonant converter. In this proposed system, a bidirectional
LLC resonant topology along with a new control scheme for the DG systems is established. Distributed Generation system consists of fuel cells, PV arrays etc. and a battery is used to store the excess amount of power generated. Thus the battery will store the excess power generated and will discharge the same power when the power generation in the DG system hinders. This two way power flow in the system helps in maintaining the continuous power supply and also the power quality will be enhanced. Two way power flow can be achieved by the LLC resonant converter. The control scheme of the proposed system is such a way that it can automatically charges and discharges the power from the battery. The forward and backward mode transition leads to the increased efficiency of the overall system and it will gain the popularity due to this unique characteristic.

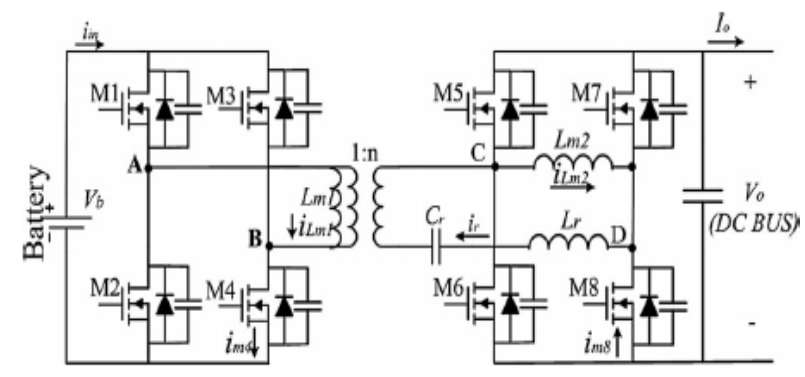

Fig.2. Proposed LLC resonant converter.

For voltage gain exceeding or equal to unity, the inductors $\mathrm{Lm} 2, \mathrm{Lr}$ and capacitor $\mathrm{Cr}$ form the resonant tank, and the magnetizing inductor Lmlof the high frequency transformer helps to achieve ZVS for switching in the primary side and thus reduces the switching losses. For gain less than unity, the inductors $\mathrm{Lr}$, capacitor $\mathrm{Cr}$ and Lm1 of the transformer form the resonant tank, and the inductor Lm2 helps to achieve ZVS for secondary side switches. In order to achieve the desired characteristics, the control scheme is very important which is turning ON and OFF the both bridges with same switching frequency. Thus, the high switching loss and high circulating energy in the converter can be avoided. The output current is always in continuous conduction mode (CCM) at all frequencies, which is different from conventional unidirectional LLC converter with different voltage gain characteristics which is more attractive.

The control scheme is very important to achieve the desired characteristics of the proposed topology. The most straightforward control scheme is turning $\mathrm{ON}$ and OFF the primary side switches and secondary side switches with same switching frequency and this is called as synchronous switching. The diagonal switches M1/M4 and M2/M3 in the input bridge are switching with $50 \%$ duty cycle and complementarily without considering the dead time. The gate drive signals for M5/M8 and M6/M7 in the output bridge are the same as those for M1/ M4 and $\mathrm{M} 2 / \mathrm{M} 3$, respectively, which can be regarded as the 


\section{International Journal of Innovative Research in Electrical, Electronics, Instrumentation and Control Engineering ISO 3297:2007 Certified \\ Vol. 5, Issue 1, January 2017}

synchronous control. The switching frequency is used to control output power as traditional LLC resonant converter.

Thus, the high conduction loss and poor reverse recovery problem of MOSFET body diodes in the output side can be avoided. And the current in the output side is always in continuous conduction mode (CCM) even when the switching frequency is below the resonant frequency, which is different from traditional unidirectional LLC converter. Moreover, the output characteristic such as voltage gain is also different. The converter is always operating below the resonant frequency. All the MOSFETs in the converter are switching with same frequency, but the pulse width of gate drive signals for primary side MOSFETs and secondary side MOSFETs are different according to the voltage gain.

The modes of operation of the proposed converter can be explained in three different cases of the battery or ESS status. Similar to the existing conventional LLC resonant converter, the discharging mode of battery is termed as forward mode and the charging mode of battery is termed as backward mode. In forward mode of operation, the battery delivers the energy into DC bus while in backward mode of operation, the excess energy generated by the renewable energy sources charge the battery.

A. Case 1: when energy generated by PV array is not sufficient to meet load:

In this case, energy supplied by the PV array or distributed generation system is not sufficient to meet the load demand. At this stage ESS or battery has to release energy by discharging to meet the rest load so as to keep the load current in CCM. In this mode of operation, inductors Lm2, $\mathrm{Lr}$ and capacitor $\mathrm{Cr}$ form the LLC resonant tank and magnetizing inductor Lm1 of the transformer is used to achieve ZVS for switches. For half switching cycle, the three different operating modes are as explained below.

1) Mode1 (t0 - t1): This mode of operation for this case is as shown in the fig.3. Switches M1, M4, M5 and M8 are switched $\mathrm{ON}$ at $\mathrm{t} 0$ with ZVS. The voltage across inductor Lm2 is equal to output voltage and its current increases linearly. Battery voltage is applied across the primary of the transformer and the current through magnetizing inductor also increases linearly.

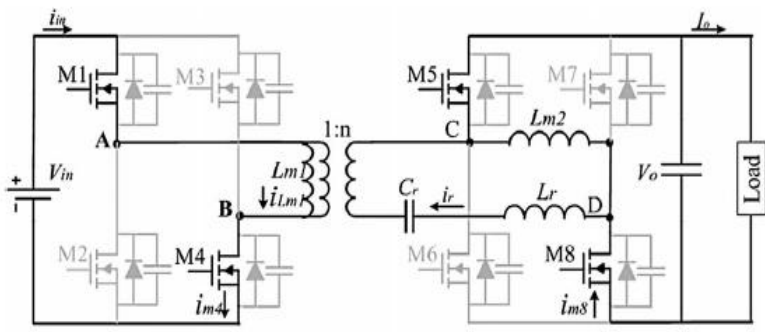

Fig.3. Operation mode of caseA mode1
In this period, inductor $\mathrm{Lr}$ is resonant with capacitor $\mathrm{Cr}$. When M5 and M8 are turned OFF at t1, this mode ends as current in resonant tank is equal to current through auxiliary inductor, so switches turn OFF with ZCS.

2) Mode $2(\mathrm{t} 1-\mathrm{t} 2)$ :The load is not connected with resonant tank, output capacitor supplies energy to the load. In this period, inductors $\mathrm{Lr}, \mathrm{Lm} 2$ and capacitor $\mathrm{Cr}$ form the resonant tank. This mode of operation is as illustrated in the below figure 4 .

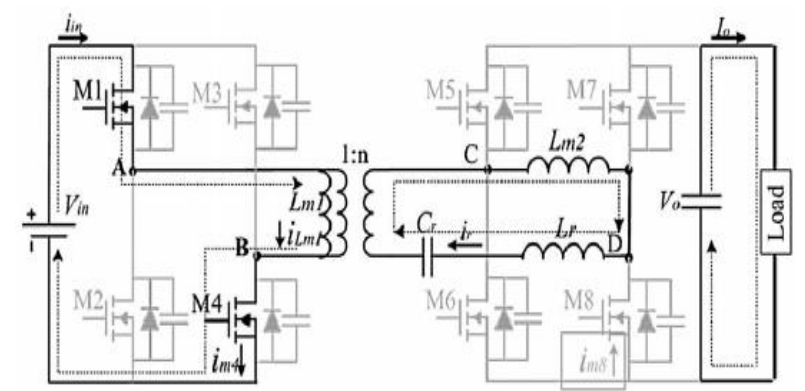

Fig.4 Operation mode of caseA mode2

3) 3) Mode 3 (t2 - t3): Switches M1 and M4 are switched OFF at $\mathrm{t} 2$. The current is made to flow through the body diodes of the MOSFETs M2 and M3 in the primary side of the transformer. The secondary side current flows through the body diodes of switches M6 and M7 and then they will switch ON with ZVS. This mode of operation is shown in figure5.

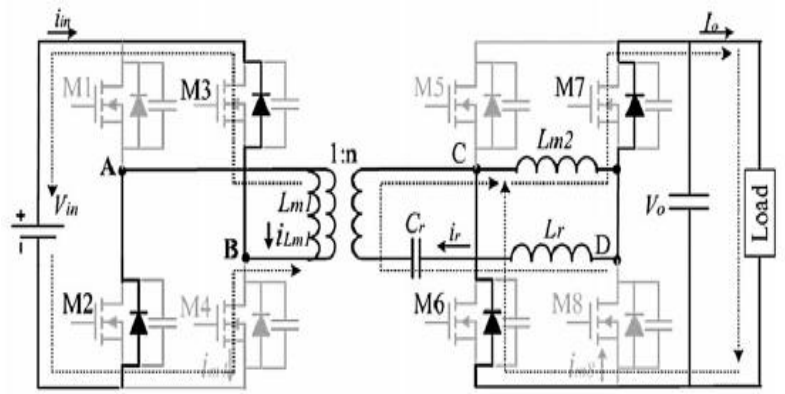

Fig.5 Operation mode of caseA mode 3

B. Case 2: when energy generated by PV array exactly matches the load:

Here the energy generated by the distributed system or PV array is just sufficient to meet the load demand. The energy transferred between the load and the ESS will be zero. Here also there are three modes of operation for a half switching cycle which are as explained below.

1) Mode 1 (t0-t1): Switches M1 and M4 are turned at the beginning of the cycle with ZVS. The current flow in the secondary side of the transformer is due to PV array only and the resonance begins at LLC circuit. This period ends when switches M5 and M8 are turned off at $\mathrm{t} 1$ period. This mode of operation is illustrated in the below figure6. 
IJIREEICE

\section{International Journal of Innovative Research in Electrical, Electronics, Instrumentation and Control Engineering \\ ISO 3297:2007 Certified \\ Vol. 5, Issue 1, January 2017}

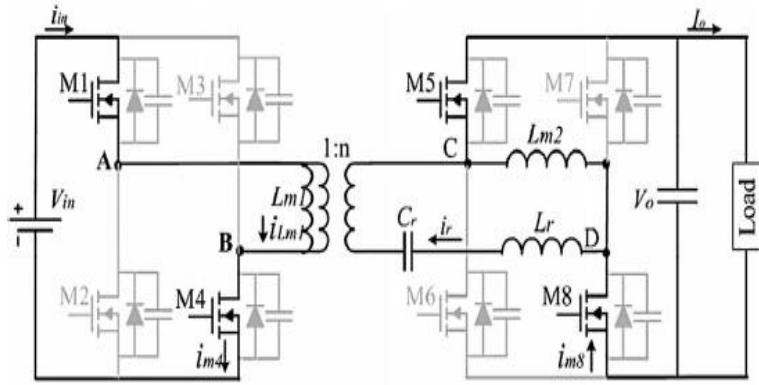

Fig.6. Operation mode of case 2 mode1

2) Mode 2 (t1-t2):In this mode of operation, secondary current still flows through the body diodes of the switches and this mode ends when M1 and M4 are switched off at t1. This mode of operation is clearly shown in the below figure7.

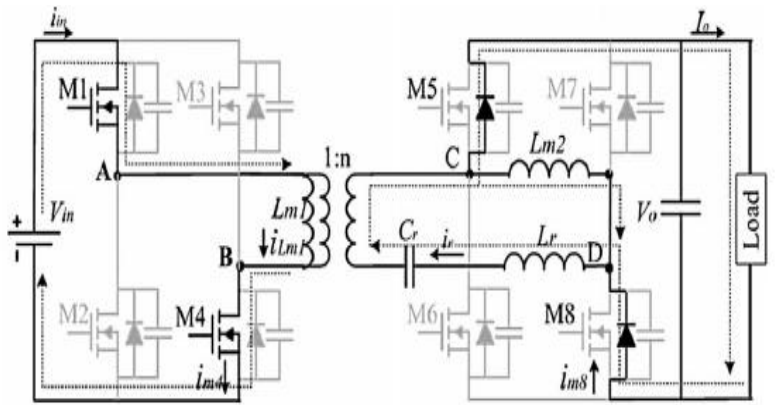

Fig7. Operation mode of case 2 mode2

3) Mode 3 (t2-t3): This mode of operation is illustrated in the figure8. In the primary side, parasitic capacitors of switches M2 and M3 are discharged and through their body diodes current flow takes place. This mode ends when M1 and M4 voltages reach zero and M2 and M3 are turned on with ZVS in next half cycle.

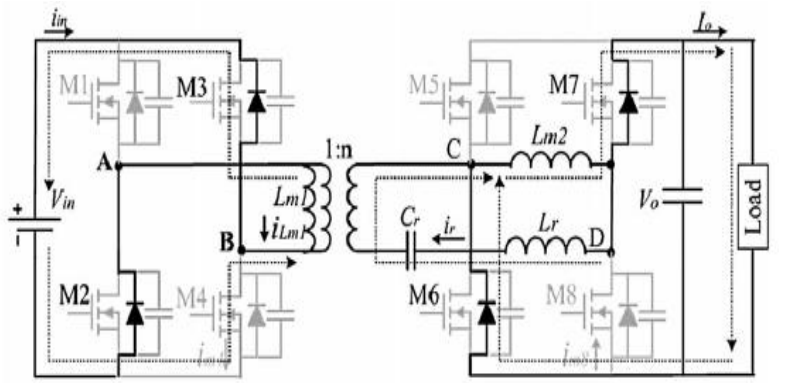

Fig8.Operation mode of case 2 mode3

C. Case 3: when excess energy is generated by PV array than load demand:

In this case, the energy generated by the PV array is larger than the load and this energy has to be stored in the ESS. Here battery will get charged by that excess energy generated as the converter operates in backward mode of operation. The three different modes of operation for this case for a half switching cycle is as explained below.
1) Mode 1 (t0-t1):This mode of operation is similar to that of the mode 1 of case 1 except the converter current is negative i.e. current flows into the battery as the current flows from secondary side to primary side of the transformer. This mode ends when M5 and M8 are turned off at $\mathrm{t} 1$. This mode of operation is illustrated as shown in the figure9.

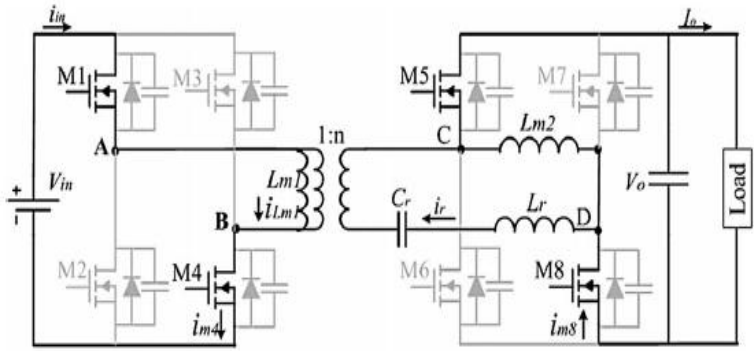

Fig9. Operation mode of case 3 mode 1

2) Mode $2(t 1-t 2):$ When M5 and M8 are turned OFF, their parasitic capacitors are charged and discharges the parasitic capacitors of opposite switches and this mode ends when M1 and M4 are turned off at the end of t1 period. This mode of operation is as shown in fig. 10 .

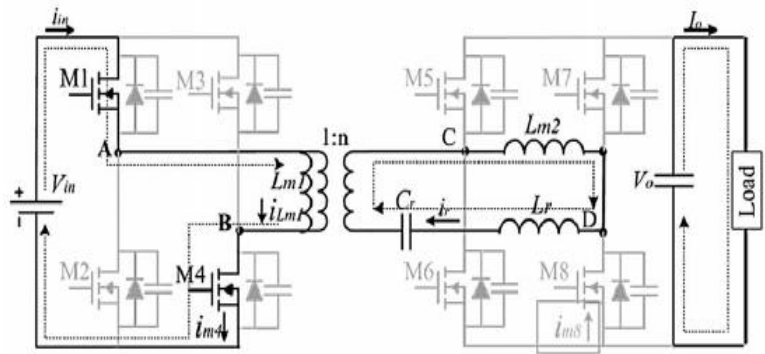

Fig10. Operation mode of case 3 mode2

3) Mode $3(\mathrm{t} 2-\mathrm{t} 3)$ : This mode is similar to that of mode 3 of case 1 except the current flows from secondary side to primary side. When the voltage across conducting switches reaches output voltage next half cycle will commence by turning $\mathrm{ON}$ the other complimentary switches. From the analysis of modes of operation for the proposed converter, it is clear that the converter operates with automatic transition and efficiency can be improved. This mode is as shown in figure 11.

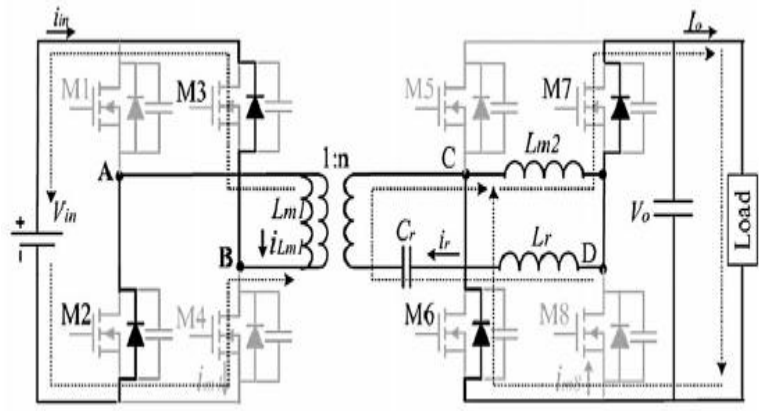

Fig.11. Operation mode of case 3 mode3 


\section{IJIREEICE \\ International Journal of Innovative Research in Electrical, Electronics, Instrumentation and Control Engineering \\ ISO 3297:2007 Certified \\ Vol. 5, Issue 1, January 2017}

\section{SIMULATION RESULTS}

The simulink model of the proposed topology i.e. the bidirectional LLC resonant converter for renewable energy storage system is developed using the MATLAB software package of version 2013a to verify the favorable characteristics of the converter. The simulink model of the LLC resonant converter for the proposed topologyis as shown in the fig. 11

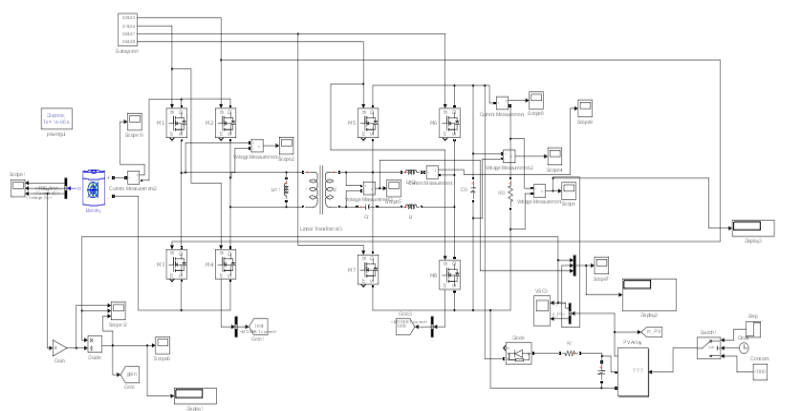

Fig.11 simulink model $f$ the proposed topology

The PV array is designed such that the energy generation will hinder below the critical level for a period from 0.5 $\mathrm{sec}$ to $1.0 \mathrm{sec}$ and again it will retain its generation at $1.0 \mathrm{sec}$. In this period from $0.5 \mathrm{sec}$ to $1.0 \mathrm{sec}$ the battery has to supply the energy to the load. The simulation is carried out with these parameters: $\mathrm{L}_{\mathrm{r}}=60 \mu \mathrm{H}, \mathrm{C}_{\mathrm{r}}=33 \mathrm{nF}, \mathrm{L}_{\mathrm{ml}}=29 \mu \mathrm{H}$, $\mathrm{L}_{\mathrm{m} 2}=400 \mu \mathrm{H}, \mathrm{f}_{\mathrm{r}}=69 \mathrm{kHzand}$ the results are screen captured as below. The output voltage, voltage gain of the converter with primary side reference and the dynamic response of the PV array, load \& battery is obtained.

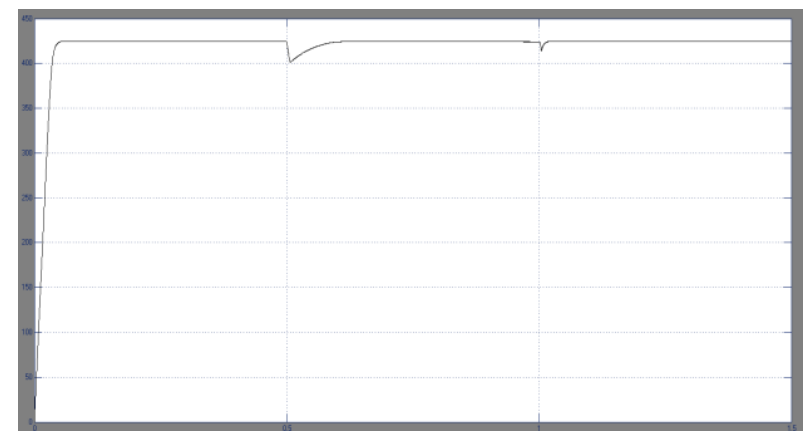

Fig.12. Output voltage of the proposed converter

Fig.12. shows the DC voltage graph at the output side which reads $400 \mathrm{~V}$ in all conditions. As the picture shows the output voltage is constant even though the PV array hinders its power generation below the par level. The PV array lowers its generation at $0.5 \mathrm{secs}$, at this time the battery discharges its stored power automatically. Due to the automatic discharge of battery the voltage at the DC bus gets maintained at the constant level. This figure depicts that once the automatic transition of the battery between its charging and discharging mode is achieved then the voltage at the output bus can be maintained at constant level.

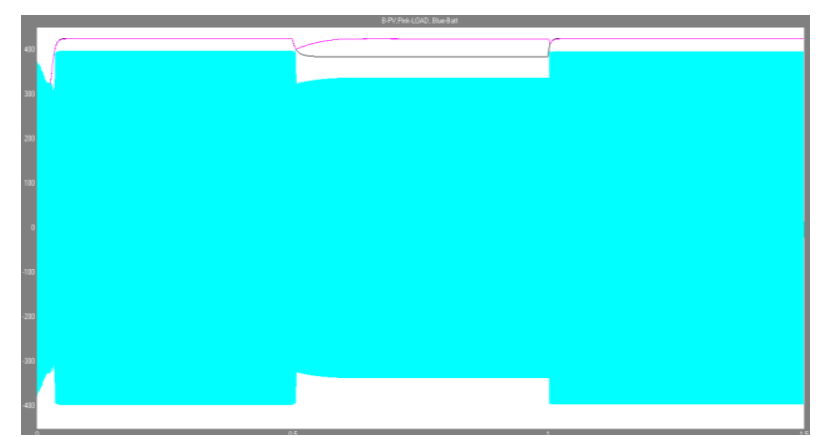

Fig.13. Dynamic response of the proposed converter

Fig.13. shows the dynamic conditions of the proposed LLC resonant converter. As mentioned earlier at $0.5 \mathrm{sec}$ the PV array power generation gets decreased below the level. At this time the battery starts discharging automatically and the voltage level at the output bus is restored to its nominal value and the voltage is maintained at the constant level. The blue colour graph indicates the battery status, black colour represents the PV array voltage level and the pink line is for the load at the output bus. As the figure depicts at $0.5 \mathrm{sec}$ the PV array lowers its generation and at this time the battery starts discharging and the pink line which shows the load voltage is maintained at the constant level.

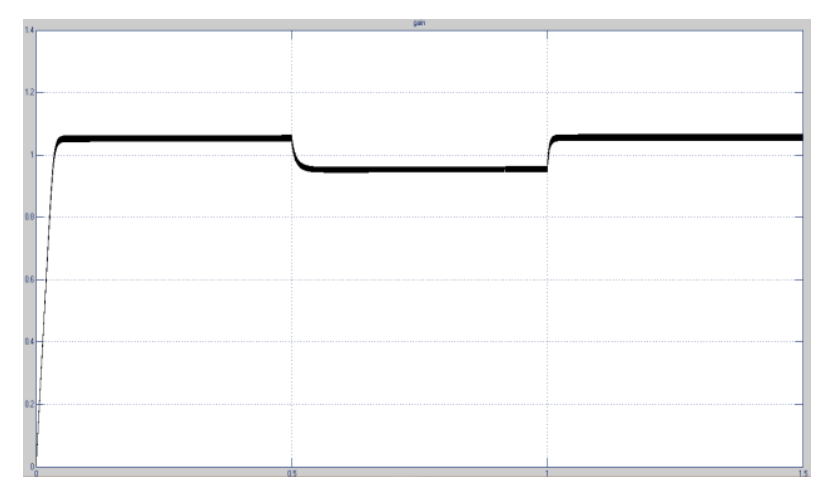

Fig.14. Voltage gain of the proposed converter

From the simulation results we can analyse the proposed LLC resonant converter in terms of output voltage and voltage gain. From the above simulation results, it is observed that the power sharing between the PV array and Battery is achieved automatically by the proposed bidirectional LLC resonant converter and the load receives the constant power during decrease in PV power generation. The performance of the proposed converter is superior to that of the other resonant converters discussed. Output voltage at the DC bus can be maintained at constant level in all the conditions and the voltage gain of the converter can be made close to one.

\section{EXPERIMENTAL SETUP}

Hardware module of the proposed LLC resonant converter has been developed with a battery of $12 \mathrm{~V} \mathrm{DC}$ supply at the input side of the transformer. PV array is connected to the 


\section{IJIREEICE \\ International Journal of Innovative Research in Electrical, Electronics, Instrumentation and Control Engineering \\ ISO 3297:2007 Certified \\ Vol. 5, Issue 1, January 2017}

DC bus which also has a resistive load and the bus is connected at the secondary side of the transformer. The turns ratio of the transformer is set to 4 which means the $12 \mathrm{~V}$ supply at the input side is stepped up to $48 \mathrm{~V}$ at the output side. A driver circuit is built to switching $\mathrm{ON}$ and OFF the MOSFETs of the dual active bridge. The hardware connection for the experimental setup is as shown in figure 15. The experimental results are verified with the simulation.

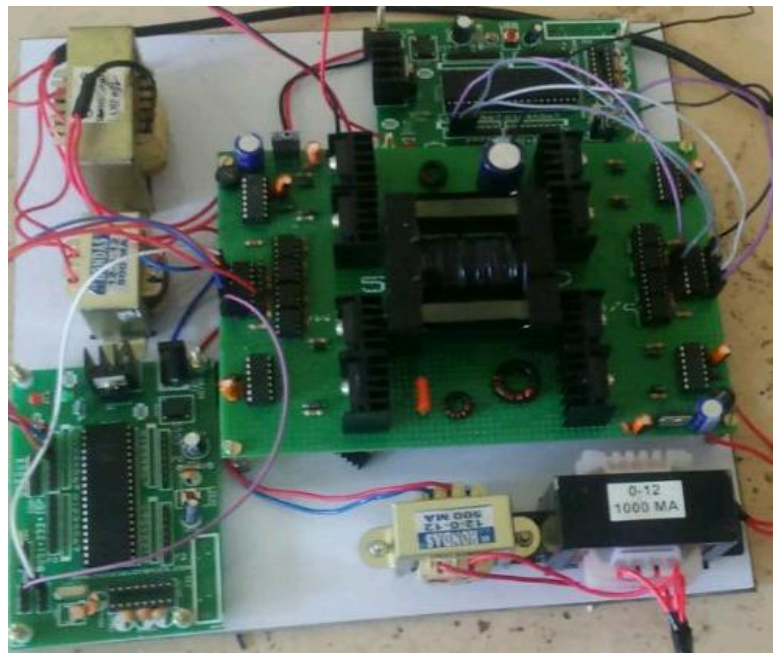

Fig15. Experimental setup for the proposed converter

A. Rectifier output voltage waveform:

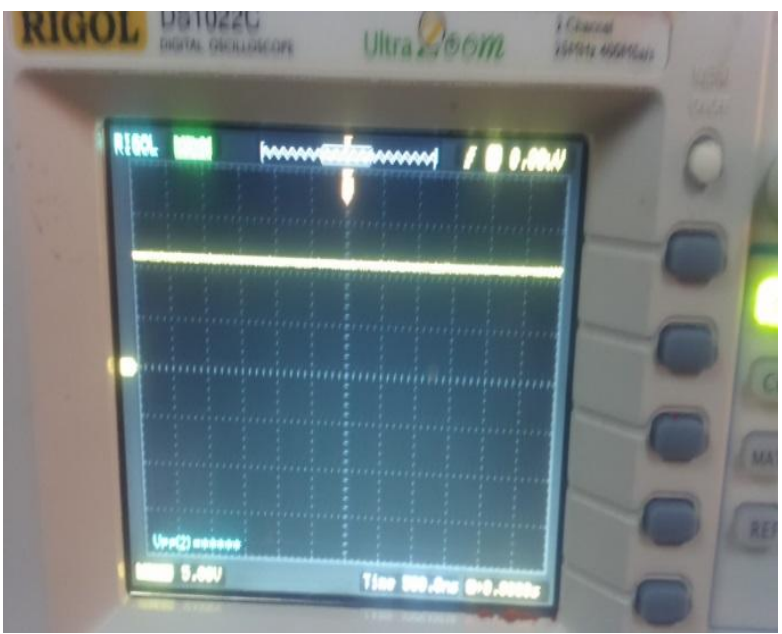

Fig16. Voltage waveform of the rectifier output

The above figure12 shows the output voltage waveform of the rectifier. It reads 2.2 units when the scale is set for $5.0 \mathrm{~V} / \mathrm{unit}$ i.e. it read $12 \mathrm{~V}$. The rectifier output voltage is $12 \mathrm{~V} \mathrm{DC}$ which is obtained from $230 \mathrm{~V}, 50 \mathrm{~Hz}$ AC supply. $230 \mathrm{~V}$ AC voltage is stepped down by a transformer and then it is fed to the rectifier to get DC power. As shown in the figure 6.5.1, channel 1 is used to measure the rectifier output voltage and it is set for 5 volts/div. and the CRO shows two and quarter units which means it measures $12 \mathrm{~V}$.
B. Gate pulses for the MOSFET switches:

The above fig17 shows the gate pulses for the MOSFET switches of the dual active bridge. The duty cycle is chosen to be $50 \%$ for the inverting bridge and $34.5 \%$ for the converting bridge. The switching frequency for both the bridges is set to the same value which is $70 \mathrm{kHz}$. Here the scale is set for $2 \mathrm{~V} / \mathrm{div}$ and it shows two and half divisions.

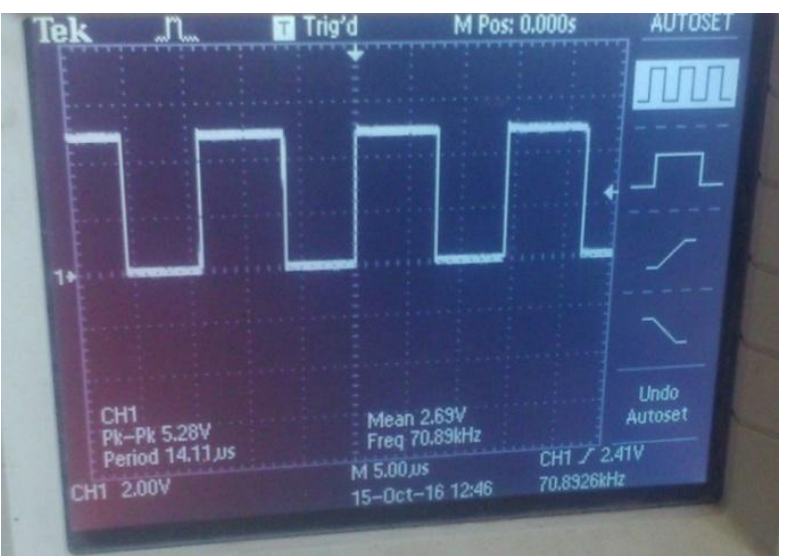

Fig.17. Gate pulses for the MOSFET switches

\section{Output Voltage:}

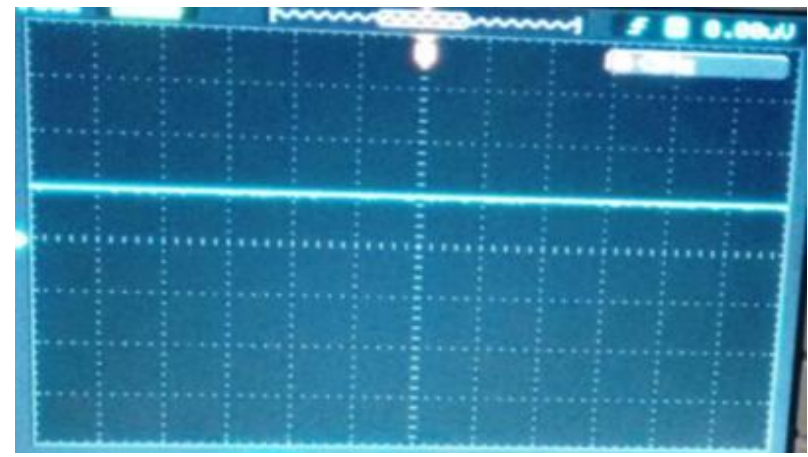

Fig.18 Output Voltage waveform

Fig.6.18. shows the output voltage at DC bus. The DC bus is maintained at the constant voltage of $48 \mathrm{~V}$. as shown in the figure the CRO reads around 1division the scale is set for $50 \mathrm{~V} / \mathrm{div}$.

\section{CONCLUSION}

The performance of the proposed bidirectional LLC resonant converter with automatic transition is investigated for renewable energy sources and energy storage systems by MATLAB simulation. With this proposed new bi-directional LLC resonant dc-dc converter, the power flow direction and output power of the proposed converter can be changed automatically and continuously. A prototype of hardware model is implemented for $12 \mathrm{~V}$ battery at the input side and the output DC bus is maintained at $48 \mathrm{~V}$. The obtained hardware results are verified with the simulation results. 


\section{IJIREEICE \\ International Journal of Innovative Research in Electrical, Electronics, Instrumentation and Control Engineering \\ ISO 3297:2007 Certified \\ Vol. 5, Issue 1, January 2017}

\section{REFERENCES}

[1] G. Ma,W. Qu, G. Yu, Y. Liu, N. Liang, andW. Li, “A zero-voltage switchingbidirectional dc-dc converter with state analysis and soft switchingorienteddesign consideration," IEEE Trans. Ind. Electron., vol. 56, no. 6,pp. 2174-2184, Jun. 2009.

[2] Y. Du, X. Zhou, S. Bai, S. Lukic, and A. Huang, "Review of nonisolated bidirectional dc-dc converters for plug-in hybrid electric vehicle charge station application at municipal parking decks," in Proc. IEEE Appl. PowerElectron. Conf., 2010, pp. 1145-1151.

[3] M. H. Kheraluwala, R. W. Gascoigne, D. M. Divan, and E. D. Baumann, "A three-phase soft-switched high-power-density dc/dc converter for high power application," IEEE Trans. Ind. Appl., vol. 27, no. 1, pp. 63-73, Jan./Feb. 1991.

[4] K. Wang, C. Y. Lin, L. Zhu, D. Qu, F. C. Lee, and J. S. Lai, "Bidirectional dc/dc converters for fuel cell systems," in Proc. IEEE Trans. Power Electron., Oct. 1998, pp. 4751.

[5] F. Krismer, S. Round, and J. W. Kolar, "Performance optimization of a high current dual active bridge with a wide operating voltage range," in Proc. IEEE Power Electron. Spec. Conf., 2006, pp. 1-7.

[6] L. Zhu, "A novel soft-commutating isolated boost full-bridge ZVS PWM dc-dc converter for bidirectional high power applications," IEEE Trans.Power Electron., vol. 21, no. 2, pp. 422-429, Mar. 2006.

[7] S. Inoue and H. Akagi, "A bidirectional dc-dc converter for an energy storage system with galvanic isolation," IEEE Trans. Power Electron., vol. 22, no. 6, pp. 2299-2306, Nov.2007.

[8] F. Krismer and J. W. Kolar, "Accurate power loss model derivation of a high-current dual active bridge converter for an automotive application," IEEE Trans. Power Electron., vol. 57, no. 3, pp. 881891, Mar.2010.

[9] C. Leung, S. Dutta, S. Baek, and S. Bhattacharya, "Design considerations of high-voltage and high-frequency three-phase transformer for solid state transformer application," in Proc. IEEE Energy Convers. Congr. Expo., 2010, pp. 1551-1558.

[10] J. Zhang, F. Zhang, X. Xie, D. Jiao, and Z. Qian, "A novel ZVS dc/dc converter for high-power applications," IEEE Trans. Power Electron., vol. 19, no. 2, pp. 420-429, Mar. 2004.

[11] T Jiang, X Chen, J Zhang and Y Wang, "Bidirectional LLC resonant converter for energy storage applications" IEEE Trans. Power Electron., Mar. 2014. 